\title{
Barriers and Facilitators to the Implementation of Home Rehabilitation Care for Disabled Older Adults: a Qualitative Study in Shandong, China
}

\section{Haixia Wang}

Shandong University Cheeloo College of Medicine https://orcid.org/0000-0002-0403-7797

\section{Yanyan Zhang}

Shandong University Cheeloo College of Medicine

Shouwei Yue ( $\nabla$ shouweiy@sdu.edu.cn )

Shandong University Cheeloo College of Medicine

\section{Research Article}

Keywords: Barriers, facilitators, home rehabilitation care, older adults, qualitative study

Posted Date: February 21st, 2022

DOI: https://doi.org/10.21203/rs.3.rs-1060383/v1

License: (c) (i) This work is licensed under a Creative Commons Attribution 4.0 International License.

Read Full License 


\section{Abstract}

Background: There has been growing international interest in-home rehabilitation care as a new method for the elderly with disabilities. However, the results of current studies about home rehabilitation care were still controversial.

Method: A descriptive qualitative research. Semi-structured face-to-face interviews were performed to collect data. The interview data were analyzed using a qualitative content analysis method.

Result: 18 nurses with different characteristics took part in interviews from 10 cities in Shandong Province. Nine themes were identified in our research, which included 5 barriers (Theme 1: Security issues; Theme 2: Strained relationship; Theme3: Lack of awareness to rehabilitation; Theme 4: Limited resources; Theme 5: Incomplete policies and laws), and 4 facilitators (Theme 1: Team cooperation; Theme 2: Home modifications; Theme3: Network support; Theme 4: Training)

Conclusion: Nurses from the rehabilitation department reported many barriers related to the implementation of home rehabilitation care. They reported facilitators to the implementation of home rehabilitation care despite the barriers, which provided practical recommendations for directions to be explored by researchers in China and elsewhere.

\section{Background}

Populations are aging at a rapidly expanding rate worldwide due to people being healthier and living longer[1]. China, a country that has the largest population in the world, with over 260 million people aged over 60 years and 190 million people aged over 65 years in 2020[2]. The aging process has led to older adults at risk of suffering from chronic and multiple age-associated diseases, which can lead to disabilities, especially physical disability and cognitive impairment in everyday life[3]. The need for longterm care and rehabilitation provided by hospitals or families were the consequences of disability, which would incur high medical costs[4]. Therefore, the shift from hospital to home care was actively implemented in many high-income countries as a potentially more effective way to enhance the quality of life of older adults with disabilities [5, 6].

Home rehabilitation care was an important part of home health services, mainly for patients with disabilities to provide individual care services in the home environment[7]. Some governments have responded to the issues of an aging population to improve their outcomes and decrease costs by introducing home rehabilitation care programs for older adults with disabilities in their homes[8, 9]. However, the results of current studies about home rehabilitation care were still controversial $[10,11]$. The potential of home rehabilitation care to help older adults with disabilities regain physical function was not clear [12].

Home rehabilitation care was in the initial stage of development in China. The "opinions on accelerating the development of rehabilitation medical work" in 2021 emphasized that we must continue to create 
new types of rehabilitation services, and actively develop community and home rehabilitation services in China[17]. Home rehabilitation care for disabled older adults was one important part of these services. However, there may be some obstacles to the implementation of home rehabilitation care in the Chinese cultural environment.

According to the national census in China, the permanent population of Shandong Province has exceeded 100 million, ranking second in China[18]. Shandong has approximately 15 million aged 65 and above older adults, accounting for approximately $15.13 \%$ of the total population in this province[19]. In addition, there was little research-based home rehabilitation care for the elderly in Shandong, China. In particular, little was known about barriers and facilitators to the implementation of home care for disabled older adults in Shandong China. Thus, this study aimed to explore and describe barriers and facilitators to the implementation of home care for disabled older adults in Shandong, China.

\section{Methods}

\subsection{Aim}

This study aimed to explore and describe barriers and facilitators to the implementation of home care for disabled older adults in Shandong, China.

\subsection{Study design and setting}

We conducted a multi-region study from June 2021 to August 2021 in Shandong, China. Descriptive qualitative research was used in this study to explore rehabilitation nurses' perceptions on barriers and facilitators to the implementation of home rehabilitation care. Reporting of the study complied with the Consolidated criteria for reporting qualitative research (COREQ) guidelines[20]. WHX is the interviewer of this study, female, studying for a Ph.D. in nursing with a research interest in rehabilitation nursing, and has received professional training on qualitative research. She had no prior contact with the interviewee and did not know each other.

\subsection{Participants}

Purposive sampling was conducted to reflect the diversity of nurses in different settings. Eligibility criteria of nurses for participation included: (1) Obtained the nurse practitioner certificate;(2) Obtained the nurse certificate of rehabilitation nursing specialist (2) Engaged in nursing rehabilitation work for more than 3 years. An invitation was sent via WeChat or email to seek rehabilitation nurses from Shandong province to participate in individual interviews. The sample size in this study was determined based on the criteria of no duplication of information and saturation of the sample size [21].

\subsection{Data collection}

Data collection was a semi-structured, face-to-face interview[22]. Interviews were conducted in a quiet and undisturbed room, and all interviewees completed a basic information questionnaire before the 
interviews. With the consent of the interviewee, we used a tape recorder to make the recording. Data collection and data analysis were iterative processes to allow new findings from the pre-interviews to inform and improve data collection for the subsequent interviews. Interviews were conducted in Chinese, and interview transcripts were translated by professional English translators. The general information questionnaire and interview outline are shown in Additional file 1.

\subsection{Statistical analysis}

Data were analyzed using the traditional content analysis method [23]. The first step in analyzing the data was to read the source material carefully and become familiar with its content. Before analyzing the data, the researcher read through the data at least twice to get a sense of the data as a whole; the second step was to mark the important ideas and concepts in the data and start open coding; the third step was to categorize the similar and related codes. Data analysis was completed in Nvivo version 11 . The results of the studies that were translated into English were further discussed by the research team to reach a final consensus.

\section{Results}

18 nurses from rehabilitation departments took part in interviews (Table 1). Interviews ranged from 20 min to $50 \mathrm{~min}$. The characteristics of participants were presented in Table 1. Nine themes were identified in our research, which included 5 barriers, and 4 facilitators. These themes were highlighted by collective quotes from participants. Best practices were embedded in the interviews and were described (Figure 1).

\subsection{Barriers}

\section{Theme 1: Security issues}

All participants were concerned about safety issues, including the personal safety of patients and nurses. Some adverse events might occur in the home environment when nurses were performing nursing operations, which might cause adverse effects on the patient's body. For example, a nurse said: "There are safety problems for old people.....we may do some invasive operations, such as.... intubation of a stomach tube or a urinary tube, and some adverse events may also occur." (No. 1) At the same time, the personal safety of nurses was also a prominent issue. the nurse might be personally attacked when a nurse-patient conflict occurred. A nurse said: "The first is safety.... It is personal safety problems, if the nurse comes to the home alone.... especially if the old people have a mental illness, the nurse might be attacked" (No. 4)

\section{Theme 2: Strained relationship}

Some nurses reported that the strained nurse-patient relationship was an obstacle to the implementation of home rehabilitation care. the nurse-patient relationship was not harmonious in the context of China's entire medical care. Some patients did not trust nurses, which might cause conflicts. For instance, a nurse stated: "as we all know, the relationship between the nurse and the patient is not harmonious. Many 
patients don't trust us. We can also.... see on the news that patients act on nurses.....it makes our nurses feel very insecure and our relationship becomes tense."(No.8)

\section{Theme 3: Lack of awareness of rehabilitation}

Several nurses acknowledged that many patients were lack of awareness to rehabilitation, and the patients could not understand that home rehabilitation care plays an important part in the recovery of body function. A nurse said: "Many patients don't know what rehabilitation is, so they certainly don't understand home rehabilitation care. They don't have this awareness at all." (No. 13) It was very necessary to raise patients' awareness of home rehabilitation care.

\section{Theme 4: Limited resources}

The participants considered that limited resources regarding home rehabilitation care in China were a significant barrier. On the one hand, the current situation was a shortage of nurses. For example, a nurse stated: "The nurses in the ward are simply not enough, and.... we often have to work overtime. We do not have extra nurses to do this job." (No. 5) On the other hand, a lack of funds would seriously hinder the development of home rehabilitation care. A nurse said: "So, for us, it's the financial challenges. The government must provide strongly funds. I think....it will be very.... difficult to make it without money" (No. 8)

\section{Theme 5: Incomplete policies and laws}

Participants often mentioned the incomplete policies and laws in the Chinese context. A nurse stated: "To successfully implement it, we should publish policies related to it.... haven't heard of any policies about it yet. I think....it will be much easier to develop with the policy support." (No. 3) Another nurse said: "The laws can protect the safety of nurses....as well as patients. But now, we do not have any laws about home rehabilitation care." (No. 6) This showed that it was necessary to have the government's policy support and the promulgation of laws to ensure the development of home rehabilitation care.

\subsection{Facilitators}

\section{Theme 1: Team cooperation}

Team cooperation was identified as a major facilitator to the implementation of home rehabilitation care. Some nurses suggested that low-skilled nurses and high-skilled nurses work together to provide home rehabilitation care for patients. For example, a nurse commented: "You can let the younger nurses and the more senior nurses together. The senior nurses can have this ability to deal with when they encounter any problems." (No. 14) Other nurses expressed that a team of nurses, doctors, and therapists should be formed to carry out their work. A nurse said: "I don't think it only needs nurses. Nurses can cooperate with doctors and therapists. In this case....the effect of home rehabilitation care will be better. After the doctor's diagnosis and evaluation, the doctor's order.... will be given by our nurses and therapists to execute." (No. 16) 


\section{Theme 2: Home modifications}

Some nurses reported that the environment was different between the home and hospital. The patient's home environment needed to be reformed to ensure the safety of patients. A nurse stated: "The patient's home needs to be changed. For example, some patients need a wheelchair, so.... it may need to remodel the steps, it can also prevent some dangerous things." (No. 16)

\section{Theme 3: Network support}

Many nurses believed that the Internet was a great contributor to the implementation of home rehabilitation care. Home rehabilitation care knowledge could be promoted through the network, and the network platform could be used to make the work more convenient. A nurse stated: "It is best to have a government-sponsored network platform, so that.... it can be applied to various regions on a large scale." (No. 6) Another nurse said: "It is convenient to use the Internet, and.... you can also use the Internet to promote our home rehabilitation care and let more people know about it." (No. 15)

\section{Theme 4: Training}

Several nurses expressed that home rehabilitation care was a great challenge for nurses from the department of rehabilitation. Rehabilitation nurses should have high qualifications to be competent for home rehabilitation care. For example, "Nurses need to be trained, and it can increase the number of professional nurses, so.... home rehabilitation care can be carried out on a large scale." (No. 6) Therefore, it was necessary for nurses from rehabilitation nurses to train about home rehabilitation care.

\section{Discussion}

This study conducted interviews with rehabilitation nurses with different characteristics from 10 cities in Shandong Province. The results of our study advance the understanding of the barriers facilitators that provide more comprehensive rehabilitation care for patients at home and promote the development of home rehabilitation care in China.

\subsection{Difficulties in implementing home rehabilitation care}

The safety of home patients and nurses was inseparable. Our research found that home rehabilitation care has safety issues for both patients and nurses, which was consistent with previous research results[24-26]. Recent research showed that adverse events in-home care were not rare. The Study on home care safety from Canada reported that $5.5 \%-15.1 \%$ of the patient experienced at least one adverse event such as falls or pressure ulcers due to inadequate safety[27-29]. In addition, the most serious risk for nurses was perhaps that of abuse and violence from patients at home. A survey of 1597 nurses on workplace violence in China showed that the rate of violence among nurses in the workplace was $61.2 \%$ within one year, including abuse, threats, physical assault, and sexual harassment[30]. 
Our findings indicated that patients with a lack of awareness of rehabilitation were an important obstacle to home rehabilitation care. A cross-sectional study of 316 stroke patients in China found that only $11.7 \%$ of patients had chosen rehabilitation services[31]. There were a limited number of studies in the China literature on home rehabilitation care services. Furthermore, home rehabilitation care services were not widespread in China, available home rehabilitation care was in the form of informal care, and rehabilitation care was still mainly concentrated in hospitals. Increased awareness was necessary related to developing home rehabilitation care and ensuring that patients would choose home rehabilitation care when they need it.

The inadequate resource was one of the most frequently mentioned barriers by rehabilitation nurses in our research, including shortages of nurses, equipment, and funds, which was consistent with previous studies[32-34]. the Italian public system of home care was described as underfunded and with the scarce provision of services in kind[33]. Accordingly, all the experts in Italian have suggested that increasing public expenditure devoted to long-term care was necessary, especially home care.

It was a challenge for most hospitals to implement home rehabilitation care due to incomplete policies and laws, which was similar to the findings of previous studies. A qualitative study from the United States indicated that there were barriers related to state or federal policies to provide care services in the home[35]. Strategic involvement of local and national bodies such as making policies and laws was highlighted as an effective way to overcome barriers [36].

\subsection{The implementation of home rehabilitation care sees light again}

Some nurses suggested that low-skilled nurses and high-skilled nurses or a team of nurses, doctors, and therapists should work together in our study, which was similar to previous research results. Home rehabilitation requires the services of a team including physicians, nurses, physical therapists, social service specialists, and nutritionists from different disciplines [37, 38].

The home-based environment is known to be a safe harbor from the uncertain outside world and an essential factor for health reform in the future generation [39]. Several studies have indicated that the emotional bond formed between the patient and the home care environment contributes to the recovery of the patient's physical functioning [40]. Home modifications could enable participants to navigate their homes more easily and safely[41]. In addition, we could provide assistive devices such as wheelchairs, raised toilets, and mobility ramps, which were highly considered to be facilitators of the rehabilitation process in the homes of elderly people with disabilities.

Some interviewed nurses reported that the network could strongly promote the implementation of home rehabilitation care. Firstly, it could make use of the network platform for home rehabilitation care more convenient. Secondly, it could promote home rehabilitation care through the Internet, and more elderly with disabilities could benefit from it. Some network technologies strongly promote the implementation of home rehabilitation care. Several studies have shown that health information technology (HIT), could exchange patient-centered health information across communities between patients, families, and 
caregivers [42-44]. virtual reality technology, as an adjunct to usual care, was beneficial in improving upper extremity function and activities of daily living function in elderly people with disabilities at home [45]. In addition, Telemedicine has also achieved some results in-home rehabilitation care [46]. Therefore, health information technology, virtual reality, and telemedicine could be used to better implement home rehabilitation care.

Several studies pointed out nurses' competence as one of the most concerning issues $[47,48]$. There are the most rigorous requirements in Washington State, where 60,000 family nurses should have at least 75 hours of training and 12 hours of education[49]. We can establish and standardize basic training through a series of in-person, on-the-job, and online modalities to ensure the development of a higher quality home care workforce[48].

\subsection{Limitations}

This study also has several limitations. First, only nurses in the rehabilitation department were included in this study. The views of physicians, therapists, and parents may differ and need to be investigated in subsequent studies. Second, the interviews were only performed and analyzed in Chinese, and the results of the study were translated into English. Although not each researcher had the opportunity to review the raw transcripts, we used an iterative process and researcher triangulation to ensure the accuracy of the study results.

\section{Conclusion}

Nurses from the rehabilitation department reported many barriers related to the implementation of home rehabilitation care. They reported facilitators to the implementation of home rehabilitation care despite the barriers. The research provides practical recommendations for directions to be explored by researchers in China and elsewhere.

\section{Abbreviation}

Consolidated criteria for reporting qualitative research (COREQ); health information technology (HIT)

\section{Declarations}

\section{Ethics approval and consent to participate}

The study was approved by the Institutional Ethical Committee, School of Nursing and rehabilitation, Cheeloo College of Medicine, Shandong University. All participants provided written informed consent before participating in the study.

\section{Consent to publish}

Not applicable. 
Availability of data and materials

The datasets in the current study are not publicly available to preserve participants' privacy. However, a de-identified dataset may be made available upon the reasonable request of the corresponding author.

\section{Competing interests}

The authors declare that they have no competing interests.

\section{Funding}

This work was supported by Research on the remote home service model for cerebrovascular diseases in Shandong Province (Grant 21CSHJ09), the Major Scientific and Technological Innovation Project in Shandong Province (Grant 2019JZZY011112). The funding bodies were not involved in the design of the study, the collection, analysis, and interpretation of data, and the preparation of the manuscript.

\section{Authors' Contributions}

WHX, ZYY, and YSW were involved in the study design and data analysis, the manuscript was completed by WHX, and all authors have read and approved the final manuscript.

\section{Acknowledgments}

Not applicable.

\section{References}

1. Johansson A, Ernsth Bravell M, Karlsson AB, Fristedt S: Valuable aspects of home rehabilitation in Sweden: Experiences from older adults. Health science reports 2021, 4(1):e249.

2. Seventh National Census. In., vol. 2021.

3. Fang EF, Scheibye-Knudsen M, Jahn HJ, Li J, Ling L, Guo H, Zhu X, Preedy V, Lu H, Bohr VA et al: A research agenda for aging in China in the 21st century. AGEING RES REV 2015, 24(Pt B):197-205.

4. Balia S, Brau R: A country for old men? Long-term home care utilization in Europe. HEALTH ECON 2014, 23(10):1185-1212.

5. Wiles JL, Leibing A, Guberman N, Reeve J, Allen RES: The meaning of "aging in place" to older people. The Gerontologist 2012, 52(3):357-366.

6. Gillsjö C, Schwartz-Barcott D, von Post I: Home: the place the older adult cannot imagine living without. In., vol. 11; 2011: 10.

7. Bookwala J, Zdaniuk B, Burton L, Lind B, Jackson S, Schulz R: Concurrent and long-term predictors of older adults' use of community-based long-term care services: the Caregiver Health Effects Study. J AGING HEALTH 2004, 16(1):88-115. 
8. Bauer A, Fernandez J, Henderson C, Wittenberg R, Knapp M: Cost-minimisation analysis of home care reablement for older people in England: A modelling study. HEALTH SOC CARE COMM 2019, 27(5):1241-1250.

9. Lewin G, Allan J, Patterson C, Knuiman M, Boldy D, Hendrie D: A comparison of the home-care and healthcare service use and costs of older Australians randomised to receive a restorative or a conventional home-care service. In., vol. 22; 2014: 328-336.

10. Wysocki A, Butler M, Kane RL, Kane RA, Shippee T, Sainfort F: Long-Term Services and Supports for Older Adults: A Review of Home and Community-Based Services Versus Institutional Care. J AGING SOC POLICY 2015, 27(3):255-279.

11. Blackburn J, Locher JL, Kilgore ML: Comparison of Long-term Care in Nursing Homes Versus Home Health: Costs and Outcomes in Alabama. In., vol. 56; 2016: 215-221.

12. Chiang $Y$, Hsu H, Chen $C$, Chen $C$, Chang-Lee S, Chen Y, Hsu S: Evaluation of Reablement Home Care: Effects on Care Attendants, Care Recipients, and Family Caregivers. INT J ENV RES PUB HE 2020, 17(23):8784.

13. Notice on Issuing Opinions on Accelerating the Development of Rehabilitation Medical Work. In., vol. 2021.

14. Shandong Provincial Bureau of Statistics Media reports [Authoritative release] Shandong's permanent population exceeds 100 million, ranking second in the country. In., vol. 2021.

15. Shandong Provincial Statistics Bureau Census Bulletin The main data of the seventh national census of Shandong Province. In., vol. 2021.

16. Tong A, Sainsbury P, Craig J: Consolidated criteria for reporting qualitative research (COREQ): a 32item checklist for interviews and focus groups. International journal for quality in health care : journal of the International Society for Quality in Health Care 2007, 19(6):349-357.

17. Hennink MM, Kaiser BN, Marconi VC: Code Saturation Versus Meaning Saturation: How Many Interviews Are Enough? QUAL HEALTH RES 2017, 27(4):591-608.

18. Kallio H, Pietilä A, Johnson M, Kangasniemi M: Systematic methodological review: developing a framework for a qualitative semi-structured interview guide. J ADV NURS 2016, 72(12):2954-2965.

19. Graneheim UH, Lundman B: Qualitative content analysis in nursing research: concepts, procedures and measures to achieve trustworthiness. NURS EDUC TODAY 2004, 24(2):105-112.

20. Schaepe C, Ewers M: "I see myself as part of the team" - family caregivers' contribution to safety in advanced home care. BMC nursing 2018, 17:40.

21. Hignett S, Edmunds Otter M, Keen C: Safety risks associated with physical interactions between patients and caregivers during treatment and care delivery in Home Care settings: A systematic review. INT J NURS STUD 2016, 59:1-14.

22. Irani E, Hirschman KB, Cacchione PZ, Bowles KH: The Role of Social, Economic, and Physical Environmental Factors in Care Planning for Home Health Care Recipients. RES GERONTOL NURS 2020, 13(3):130-137. 
23. Sears N, Baker GR, Barnsley J, Shortt S: The incidence of adverse events among home care patients. International journal for quality in health care : journal of the International Society for Quality in Health Care 2013, 25(1):16-28.

24. Sears N, Baker GR, Barnsley J, Shortt S: The incidence of adverse events among home care patients. International journal for quality in health care : journal of the International Society for Quality in Health Care 2013, 25(1):16-28.

25. Masotti P, McColl MA, Green M: Adverse events experienced by homecare patients: a scoping review of the literature. International journal for quality in health care : journal of the International Society for Quality in Health Care 2010, 22(2):115-125.

26. Yan Y, Shujie S: Analysis of the current situation and influencing factors of violence in nurses' workplaces in Harbin. Journal of Nursing 2015, 30(12):1-5.

27. Jianxia L, Jin C, Juan Z, Rong T, Zhengping C, Tingting L, Jiaojiao G: Investigation on the status of community rehabilitation of stroke patients in Yancheng City. Massage and Rehabilitation Medicine 2021, 12(18):20-23.

28. Siemonsma P, Döpp C, Alpay L, Tak E, Meeteren NV, Chorus A: Determinants influencing the implementation of home-based stroke rehabilitation: a systematic review. DISABIL REHABIL 2014, 36(24):2019-2030.

29. Gori C: Home care in Italy: a system on the move, in the opposite direction to what we expect. HEALTH SOC CARE COMM 2012, 20(3):255-264.

30. Ree E, Johannessen T, Wiig S: How do contextual factors influence quality and safety work in the Norwegian home care and nursing home settings? A qualitative study about managers' experiences. BMJ OPEN 2019, 9(7):e25197.

31. Brody AA, Arbaje Al, DeCherrie LV, Federman AD, Leff B, Siu AL: Starting Up a Hospital at Home Program: Facilitators and Barriers to Implementation. J AM GERIATR SOC 2019, 67(3):588-595.

32. Stocker R, Bamford C, Brittain K, Duncan R, Moffatt S, Robinson L, Hanratty B: Care home services at the vanguard: a qualitative study exploring stakeholder views on the development and evaluation of novel, integrated approaches to enhancing healthcare in care homes. BMJ OPEN 2018, 8(3):e17419.

33. Steihaug S, Lippestad J, Isaksen H, Werner A: Development of a model for organisation of and cooperation on home-based rehabilitation - an action research project. DISABIL REHABIL 2014, 36(7):608-616.

34. Polat Ü, Bayrak Kahraman B, Kaynak 0, Görgülü Ü: Relationship among health-related quality of life, depression and awareness of home care services in elderly patients. GERIATR GERONTOL INT 2016, 16(11):1211-1219.

35. OECD Health Ministerial Statement - The next generation of health reforms - OECD. In., vol. 2021.

36. Dijkstra K, Pieterse M, Pruyn A: Physical environmental stimuli that turn healthcare facilities into healing environments through psychologically mediated effects: systematic review. J ADV NURS 2006, 56(2):166-181. 
37. Szanton SL, Leff B, Wolff JL, Roberts L, Gitlin LN: Home-Based Care Program Reduces Disability And Promotes Aging In Place. Health affairs (Project Hope) 2016, 35(9):1558-1563.

38. Cipriano PF, Bowles K, Dailey M, Dykes P, Lamb G, Naylor M: The importance of health information technology in care coordination and transitional care. NURS OUTLOOK 2013, 61(6):475-489.

39. Stolee P, Steeves B, Glenny C, Filsinger S: The use of electronic health information systems in home care: facilitators and barriers. Home healthcare nurse 2010, 28(3):167-179, 180-181.

40. Cipriano PF, Bowles K, Dailey M, Dykes P, Lamb G, Naylor M: The importance of health information technology in care coordination and transitional care. NURS OUTLOOK 2013, 61(6):475-489.

41. Laver KE, Lange B, George S, Deutsch JE, Saposnik G, Crotty M: Virtual reality for stroke rehabilitation. The Cochrane database of systematic reviews 2017, 11(11):D8349.

42. Johnston $B$, Kidd L, Wengstrom $Y$, Kearney $N$ : An evaluation of the use of Telehealth within palliative care settings across Scotland. In., vol. 26; 2012: 152-161.

43. Swedberg L, Chiriac EH, Törnkvist L, Hylander I: From risky to safer home care: health care assistants striving to overcome a lack of training, supervision, and support. INT J QUAL STUD HEAL 2013, 8:20758.

44. Stone RI, Bryant NS: The Future of the Home Care Workforce: Training and Supporting Aides as Members of Home-Based Care Teams. J AM GERIATR SOC 2019, 67(S2):S444-S448.

45. Dawson SL: The SEIU Healthcare NW Training Partnership in Washington State. GENERATIONS 2016, 40(1):88-91.

\section{Table}

Table 1 The characteristics of interviewed participates 


\begin{tabular}{|c|c|c|c|c|c|c|c|c|}
\hline Number & $\begin{array}{c}\text { Date of } \\
\text { birth(year) }\end{array}$ & Hospital level & City & Job title & $\begin{array}{l}\text { Working } \\
\text { years }\end{array}$ & $\begin{array}{l}\text { Salary } \\
\text { (yuan) }\end{array}$ & Highest education & First degree \\
\hline 1 & 1982 & Secondary & Zbo & Nurse-in-charge & 19 & 6000 & Junior college & $\begin{array}{c}\text { Technical secondary } \\
\text { school }\end{array}$ \\
\hline 2 & 1989 & Tertiary & Qingdao & Nurse practitioner & 8 & 8000 & Undergraduate & Junior college \\
\hline 3 & 1990 & Secondary & Liaocheng & Nurse practitioner & 6 & 3000 & Undergraduate & Junior college \\
\hline 4 & 1990 & First-level & Zbo & Nurse practitioner & 13 & 5000 & Undergraduate & $\begin{array}{c}\text { Technical secondary } \\
\text { school }\end{array}$ \\
\hline 5 & 1989 & Tertiary & Jining & Nurse practitioner & 10 & 7000 & Undergraduate & Junior college \\
\hline 6 & 1985 & Tertiary & Jinan & Nurse-in-charge & 15 & 9000 & Undergraduate & Junior college \\
\hline 7 & 1993 & Secondary & Zaothuang & Nurse practitioner & 5 & 4000 & Undergraduate & Junior college \\
\hline 8 & 1991 & Tertiary & Jining & Nurse practitioner & 9 & 8000 & Undergraduate & Junior college \\
\hline 9 & 1993 & Secondary & Weifang & Nurse practitioner & 3 & 6500 & Undergraduate & Undergraduate \\
\hline 10 & 1972 & Secondary & Jinan & Nurse-in-charge & 30 & 7000 & Undergraduate & $\begin{array}{l}\text { Technical secondary } \\
\text { school }\end{array}$ \\
\hline 11 & 1987 & Tertiary & Binzhou & Nurse-in-charge & 10 & 8000 & Undergraduate & Undergraduate \\
\hline 12 & 1983 & Tertiary & Jinan & Nurse-in-charge & 14 & 8000 & Undergraduate & Undergraduate \\
\hline 13 & 1977 & Secondary & Lirryi & $\begin{array}{l}\text { Associate professor of } \\
\text { mursing }\end{array}$ & 24 & 8000 & Undergraduate & $\begin{array}{c}\text { Technical secondary } \\
\text { school }\end{array}$ \\
\hline 14 & 1982 & Tertiary & Jinan & murse-in-charge & 19 & 8000 & Undergraduate & $\begin{array}{l}\text { Technical secondary } \\
\text { school }\end{array}$ \\
\hline 15 & 1983 & Secondary & Dethou & murse-in-charge & 12 & 6000 & Junior college & Junior college \\
\hline 16 & 1988 & Tertiary & Jinan & murse practitioner & 15 & 8000 & Undergraduate & $\begin{array}{c}\text { Technical secondary } \\
\text { school }\end{array}$ \\
\hline 17 & 1976 & Tertiary & Jinan & $\begin{array}{l}\text { associate professor of } \\
\text { mursing }\end{array}$ & 24 & 20000 & Undergraduate & $\begin{array}{l}\text { Technical secondary } \\
\text { school }\end{array}$ \\
\hline 18 & 1987 & Tertiary & Jining & murse-in-charge & 10 & 12000 & Undergraduate & Undergraduate \\
\hline
\end{tabular}

Figures 
Barriers

Security issues

Strained relationship

Lack of awareness to rehabilitation

Limited resources

In complete policies and laws

\section{Facilitators}

Team cooperation

Home modifications

Network support

Training

\section{Figure 1}

Summary of the barriers and facilitators of the implementation of home rehabilitation care

\section{Supplementary Files}

This is a list of supplementary files associated with this preprint. Click to download.

- Additionalfile1..docx

- COREQguidelines.docx 